\title{
Sadismo ou Demonismo na poética de Machado de Assis
}

\author{
Fabiana Gonçalves
}

\section{SciELO Books / SciELO Livros / SciELO Libros}

GONÇALVES, F. Sadismo ou Demonismo na poética de Machado de Assis. In MAGALHÃES, ACM., et al., orgs. O demoníaco na literatura [online]. Campina Grande: EDUEPB, 2012. pp. $177-$ 187. ISBN 978-85-7879-188-9. Available from SciELO Books <http://books. scielo.org>.

\section{(2)(1)(2)}

All the contents of this work, except where otherwise noted, is licensed under a Creative Commons Attribution-Non Commercial-ShareAlike 3.0 Unported.

Todo o conteúdo deste trabalho, exceto quando houver ressalva, é publicado sob a licença Creative Commons Atribuição Uso Não Comercial - Partilha nos Mesmos Termos 3.0 Não adaptada.

Todo el contenido de esta obra, excepto donde se indique lo contrario, está bajo licencia de la licencia Creative Commons Reconocimento-NoComercial-CompartirIgual 3.0 Unported. 


\section{Sadismo ou Demonismo na poética de Machado de Assis}

Fabiana Gonçalves (UNESP) ${ }^{1}$

"O gosto pela crueldade apresenta traços humanos."

Umberto Eco (História da feiúra)

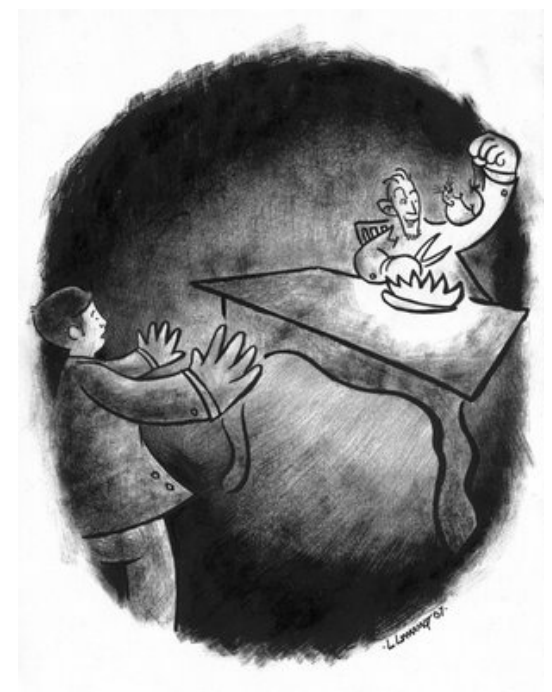

O soneto "À Ilma. Sra. D. P. J. A.”, dedicado a uma certa D. Petronilha, marca "até melhor aviso", para usar uma expressão de José Galante de Sousa, o início da carreira literária de Machado de Assis.

1 Doutoranda em Letras na UNESP/Assis. Recentemente publicou artigos sobre a poesia de Machado de Assis em revistas eletrônicas especializadas e atuou como membro do corpo editorial da Miscelânea: Revista de Pós Graduação em Letras. E-mail: fabivotu@ yahoo.com.br. 
Desde a publicação desse poema no Periódico dos Pobres em 3 de outubro de 1854 até 1908, Machado escreveu cerca de duzentos poemas, dedicou-se à tradução de poetas clássicos, contemporâneos, desconhecidos ou canônicos, e ainda produziu 48 crônicas versificadas. Desse conjunto, resultou em 1901 a antologia Poesias completas. Nesse volume, o poeta reeditou alguns dos poemas recolhidos em seus três primeiros livros de poesia - Crisálidas (1865), Falenas (1870) e Americanas (1875) - e apresentou ao público sua derradeira coletânea: Ocidentais.

Com relação ao exercício poético observado nessa última compilação, Cláudio Murilo Leal ressalta: "Em Ocidentais Machado de Assis domina inteiramente os segredos do artesanato poético, a par de ter adquirido uma cosmovisão que o permite superar o episódico e construir uma poesia em que são questionados os metafísicos problemas do Ser e do Mundo" (LEAL, 2008, p. 144). De fato, a maioria das composições responsáveis pelo reconhecimento de Machado de Assis poeta está nesse volume. Dentre as mais cultuadas, estão "Circulo vicioso"; "A mosca azul", "Uma criatura", "Mundo interior", e as recriações de "The raven", de Edgar Allan Poe, e do solilóquio shakespeariano "To be or not to be". Embora pouco lembrado, também podemos incluir nesta lista o poema "Suave mari magno".

Lançado pela primeira vez na Revista Brasileira em 15/01/1880 e posteriormente coletado nas Ocidentais, "Suave mari magno" apresenta um tema pouco comum na obra machadiana: o prazer diante do sórdido. Validando a presença do sadismo na poética de Machado de Assis, a narrativa de "A causa secreta", conto originalmente publicado na Gazeta de Notícias em 01/08/1885 e compilado dez anos depois em Várias histórias, também se dedica ao temário sádico.

\section{Khatarsis e sadismo}

Reconhecido também por purificação, o vocábulo catarse, pouco explicado inclusive pelo próprio Aristóteles, tem rendido muitas e variadas discussões nas mais diversas áreas do conhecimento. Um dos pontos-chave da poética aristotélica, o prazer catártico refere-se grosso modo às emoções suscitadas pela tragédia. Dito de outra maneira e igualmente em poucas palavras, na arte a catarse associa-se às reações 
apresentadas por indivíduos quando vivenciam uma experiência estética. Após a contemplação artística, “... estas almas se sentem aliviadas agradavelmente. O mesmo acontece com as almas presas de compaixão ou de terror ou de outra... paixão". ${ }^{2}$. Sob esse prisma, a teoria de Aristóteles nos induz a refletir sobre uma possível nuance desse mesmo fenômeno: o sadismo.

Modernamente difundida por Marques de Sade, cujo nome deu origem ao termo, a arte sádica, entre outros aspectos, busca demonstrar como o gosto pela crueldade está incrustado à natureza humana. Contemporâneo de Sade, Friedrich Schiller ao discorrer sobre a "disposição natural" do homem ao trágico observa: "É um fenômeno geral na nossa natureza, que aquilo que é triste, terrível e mesmo horrendo nos atraia com um fascínio irresistível; que certas cenas de dor e terror nos afastem, mas com a mesma força nos atraiam de volta [...]" (SCHILLER, apud ECO, 2007, p. 220).

De fato, conforme realça Umberto Eco (2010, p 222), desde os tempos dos anfiteatros romanos onde os rituais de suplício e execuções ganhavam contornos de espetáculos, a história registra atos de violência servidos em verdadeiros banquetes a fim de satisfazer o anseio popular. Ficcionalmente, o sadismo apresenta-se, sobretudo, de modo metafórico e quase sempre subscreve uma intenção subliminar de condenação ou denúncia às práticas violentas e/ou opressivas. Inúmeros autores retrataram artisticamente a violência enquanto estímulo do prazer e com isso relegaram aos pósteros inequívocos testemunhos verbais/pictóricos de diversas vertentes do comportamento sádico. Sade, escritor responsável pela popularização da atividade literária em torno do sadismo, além de celebrar o desprezo pelo corpo alheio, tacitamente também utilizou as diversas faces de sua obra como forma de desmascaramento dos poderes exploratórios da França do século XVIII.

Ampliando os horizontes sádicos, um dos escritores preferidos de Machado de Assis, Edgar Allan Poe, evidenciou no conto "O gato preto" que a violência não atinge apenas os humanos. A tortura infligida

2 O trecho transcrito consta do texto introdutório da Arte poética. A autoria, embora os comentários nesta edição nos levem a crer que o tradutor seja também o introdutor, não é identificada. Para mais detalhes ver: ARISTÓTELES. Arte poética. [Tradução de Pietro Nassetti] São Paulo: Martin Claret, 2003. 
a um gato na narrativa de Poe assemelha-se muito com o martírio aplicado por Fortunato ao rato em "A causa secreta". Convém ressaltar a proximidade de Machado de Assis com os textos do escritor, lidos diretamente do original. A predileção e familiaridade à literatura de Poe foram registradas por diversas vezes pelo próprio poeta e enfatizadas através de recriações, citações e alusões a obras do autor norte-americano. Longe de fermentar ainda mais os imbróglios envolvendo o paradigma de originalidade na obra machadiana, importa notar as ressonâncias entre a personalidade do causador de tanta aflição em "A causa secreta" e a do protagonista impiedoso de "O barril de Amontillado", publicado em 1846. Ambas as personagens poderiam ser classificadas de amantes do sofrimento. Além disso, talvez tenha saído dessa narrativa o nome da personagem machadiana ${ }^{3}$.

Duplamente vítima, o cão aparece em "Suave mari magno" padecendo de uma crise convulsiva e ao mesmo tempo protagonizando um espetáculo a céu aberto. Aos curiosos, deleite garantido pela dor alheia. Apenas coincidência ou propositadamente uma tentativa de atenuar os efeitos da violência, fato é que tanto no conto quanto no poema as vítimas das ações sádicas são animais, um rato e um cão respectivamente. No poema, a curiosidade dos transeuntes os detém perante a tragicidade da morte, e no conto, a fascinação de Fortunato pela tortura evita uma execução fatal instantânea. Assim, sob pretextos duvidosos, a personagem aprecia lentamente a destruição gradual do rato. Contudo, quando o objeto de prazer de Fortunato materializa-se na figura do amigo Garcia aos prantos diante do cadáver de Maria Luísa, a "justificativa" utilizada anteriormente (a personagem sádica atribui ao rato a destruição de um documento, por isso a tortura) dilui-se por completo.

Produzidas na mesma década, as duas composições retratam a privação de liberdade, o desfiguramento e o sofrimento alheio como fontes prazerosas. Passemos então aos pormenores sádicos promulgados por "Suave mari magno" e "A causa secreta".

3 No início do conto de Poe, o narrador apresenta Fortunato ao leitor: 'The thousand injuries of Fortunato I had borne as I best could ; but when he ventured upon insult, I vowed revenge.' "Eu aguentara as incontáveis injúrias de Fortunato da melhor forma possível, mas quando ele se atreveu a me insultar jurei vingança”" (Tradução de Guilherme da Silva Braga). 


\section{A curiosidade sádica em verso e prosa}

Recuperando as palavras iniciais do segundo volume da obra De rerum natura (Sobre a natureza das coisas), de Titus Lucretius Carus que viveu durante o século I a.C, Machado de Assis intitula o poema e ao fazê-lo ilumina um dos maiores poetas e filósofos de língua latina. Lucrécio, conforme ficou conhecido no idioma português, poeticamente afirma: "Suave, mari magno turbantibus aequora ventis e terra magnum alterius spectare laborem; non quia vexari quemquamst iucunda voluptas, sed quibus ipse malis careas quia cernere suavest". ${ }^{4}$ Embora relacionado ao epicurismo, cuja doutrina prega o prazer através da libertação dos temores e das culpas, Lucrécio lança com essa passagem as bases para "Suave mari magno".

A alusão ao fragmento latino imediatamente no pórtico do poema introduz o leitor em um universo polarizado pela dor e pelo alívio. Por um lado, o trecho de Lucrécio, assim como os versos machadianos, expõe as intempéries sofridas por determinados seres, e por outro o bem-estar experimentado por aqueles que se julgam salvos dos mesmos infortúnios. Afora a similitude inicial evidenciada pelo título, a composição machadiana afasta-se do pensamento latino, na medida em que descarta a ideia genuína e desinteressada do alívio para potencializar o prazer diante do sofrimento. Estruturado sob a forma do soneto, estrutura poética designada tradicionalmente para expressão do belo, "Suave mari magno" recorre a vocábulos ligados à doença, à metamorfose, à morte enfim, para simbolizar o gosto humano pela crueldade.

Lançado no mesmo ano de Memórias póstumas de Brás Cubas, cujo capítulo reservado para o delírio do defunto-autor apresenta a figura da natureza alegorizada como "mãe e inimiga" divertindo-se com a agonia alheia, "Suave mari magno" recebeu diversas interpretações. Para Lúcia Miguel Pereira (1988, p. 236), os versos traduzem um drama autobiográfico. Em decorrência das crises epilépticas, Machado de Assis teria

4 “É bom, quando os ventos revolvem a superficie do grande mar, ver da terra os rudes trabalhos por que estão passando os outros; não porque haja qualquer prazer na desgraça de alguém, mas porque é bom presenciar os males que não se sofrem. É bom também contemplar os grandes combates de guerra travados pelos campos sem que haja da nossa parte qualquer perigo." (Tradução de Agostinho da Silva) 
transposto para os versos a humilhação e indiferença sentidas durante as convulsões sofridas em público. Abaixo, os quartetos dedicados à descrição das deformidades causadas pelo ataque:

Lembra-me que, em certo dia,

$\mathrm{Na}$ rua, ao sol de verão,

Envenenado morria

Um pobre cão.

Arfava, espumava e ria,

De um riso espúrio e bufão,

Ventre e pernas sacudia

Na convulsão. ${ }^{5}$

Com efeito, Machado pode ter retratado um episódio particular em "Suave mari magno", no entanto, o meio empregado para desenvolver a tópica desvincula as ações versejadas de uma experiência unicamente pessoal e as conecta ao universal humano. A construção de uma personagem antropomorfizada - "De um riso espúrio e bufão" -, atrelada à ironia machadiana, responsável pela caracterização de um sorriso fake e jocoso ao cão, expande o horizonte de leitura, sugerindo assim outros caminhos interpretativos. Dessa forma, o poema revela-se, para compartilhar uma expressão difundida por Eco, "opera aperta".

Portanto, a ambuiguidade presente em "Suave mari magno" institui frestas para o leitor atento incursionar por suas camadas mais profundas e desse modo desvendar os recônditos dos versos. Seguindo esse raciocínio, o poema machadiano apresenta num primeiro nível um percurso superficial, cuja compreensão abarca o significado literal dos vocábulos, isto é, a convulsão de um cão envenenado e a permanência das pessoas diante da cena, e subliminarmente permite o aparecimento de outras possibilidades interpretativas. Ancorando-se no viés biográfico, Leal, um dos

5 As transcrições dos versos de "Suave mari magno" seguem o volume ASSIS, Joaquim Maria Machado de. Obra completa em quatro volumes: edição anotada. [Organização Aloizio Leite Neto, Ana Lima Cecílio, Heloisa Jahn]. 2. ed. Rio de Janeiro: Nova Aguilar, 2008. 3. v, p. 577. 
poucos especialistas a dedicar-se ao poeta, limita-se a observar: "'Suave mari magno" reflete o pessimismo do autor, o seu ceticismo em relação à concepção da bondade natural do homem.” (LEAL, 2008, p. 146).

Quanto à estrutura de "Suave mari magno", podemos caracterizá-la como um estandarte da linguagem cultivada pela poesia machadiana. Oscilando entre as orientações livres do romantismo e as regras do parnaso brasileiro, o poeta encapsulou os versos assimétricos de "Suave mari magno" em uma forma poética padronizada. Os dois tercetos, constituídos em ritmo ascensional tonalizado por uma voz reprovadora que reprime o comportamento do passante curioso, marcado, sobretudo, pela sequência de encerramento "Como se lhe desse gozo/ Ver padecer", seguem o mesmo modelo:

\author{
Nenhum, nenhum curioso \\ Passava, sem se deter, \\ Silencioso. \\ Junto ao cão que ia morrer, \\ Como se lhe desse gozo \\ Ver padecer.
}

Enquanto as duas estrofes iniciais descrevem a metamorfose canina, os tercetos retratam primeiramente a indiferença dos pedestres perante a tragédia encenada em plena rua e, em seguida, exprimem uma versão mais apurada desse comportamento, ou seja, demonstram a provocação do eu-poemático a respeito de um suposto deleite dos espectadores diante do sofrimento alheio. Simbolicamente, o poema evidencia a condição humana atrelada ainda aos instintos mais primitivos de crueldade e desamor. A razão para nenhum curioso, mas nenhum mesmo - como o verso enfatiza por meio da repetição do vocábulo - deixar de assistir a um show de horror e/ou evitar uma brutalidade qualquer se resume no fascínio natural do homem pelo horrendo, isso porque "O filho bruto da natureza, sem as rédeas de nenhum sentimento de humanidade, abandona-se sem pudor a esse poderoso impulso.” (SCHILLER, apud ECO, 2007, p. 220).

Fortunado, personagem de "A causa secreta", bem o sabe, pois não resiste às enfermidades físicas ou morais dos indivíduos a sua volta e no ápice de sua obsessão sádica chega a provocá-las. Além de Fortunato, o 
conto apresenta a esposa dele, Maria Luísa, e Garcia, estudante de medicina e amigo do casal. No início da história, o narrador relata como fora o encontro dos futuros amigos num teatro: "A peça era um dramalhão, cosido a facadas, ouriçado de imprecações e remorsos $[\ldots]^{6}$. Nos lances dolorosos, a atenção dele (de Fortunato) redobrava, os olhos iam avidamente de um personagem a outro, a tal ponto que o estudante suspeitou haver na peça reminiscências pessoais do vizinho."

O tempo e as oportunidades os aproximaram. Aproveitando-se da profissão do amigo, Fortunato propôs-lhe uma sociedade: a abertura de uma casa de saúde. Apesar da relutância de Garcia, o projeto concretizou-se. A dedicação de Fortunato aos doentes surpreendia o médico: "Não recuava diante de nada, não conhecia moléstia aflitiva ou repelente, e estava sempre pronto para tudo, a qualquer hora do dia ou da noite.". A amizade com o sujeito de alma misteriosa também estreitou os laços entre Garcia e Maria Luísa, e "Manso e manso, entrou-lhe o amor no coração.". À pretexto do novo trabalho, "Fortunato metera-se a estudar anatomia e fisiologia, e ocupava-se nas horas vagas em rasgar e envenenar cães e gatos.". No clímax da narrativa, a esposa, adoentada, flagrou ao lado do amigo a cena reveladora da causa secreta responsável pela personalidade estranha do marido. Ambos assistiram a tortura infligida por Fortunato a um rato. Ao executá-la, sentia: “[...] tão somente um vasto prazer, quieto e profundo, como daria a outro a audição de uma bela sonata ou a vista de uma estátua divina, alguma coisa parecida com a pura sensação estética".

Desvendada a identidade sádica de Fortunato, o quadro de Maria Luísa agravou-se. Desde então, o marido "Não a deixou mais; fitou o olho baço e frio naquela decomposição lenta e dolorosa da vida, bebeu uma a uma as aflições da bela criatura, agora magra e transparente, devorada de febre e minada de morte.". No final do conto, Garcia desesperado beija o cadáver de Maria Luísa. Fortunato não teve ciúmes, apenas embebido de prazer "saboreou tranquilo essa explosão de dor moral que foi longa, muito longa, deliciosamente longa.”.

6 As passagens de "A causa secreta" seguem o volume ASSIS, Joaquim Maria Machado de. Obra completa em quatro volumes: edição anotada. [Organização Aloizio Leite Neto, Ana Lima Cecílio, Heloisa Jahn]. 2. ed. Rio de Janeiro: Nova Aguilar, 2008. 2. v, pp. 476-483. 
Após essa síntese, necessária para seguirmos com as aproximações entre a narrativa e o poema, convém ressaltar alguns aspectos circundantes à literatura machadiana. Considerada a fortuna crítica do autor, a prosa, em contraposição à atenção dispensada a sua produção em verso, recebeu inúmeros enfoques. Em Machado de Assis: um escritor nos trópicos (1998), Patrícia Lessa Flores da Cunha discute as confluências entre a atividade contística do autor brasileiro e a de Poe. De acordo com a ensaísta, o poeta norte-americano concebeu a unidade de efeito para levar seus leitores, ainda que dispersos em lugares diferentes, a sentir com a mesma intensidade o conteúdo de sua prosa. Segundo Cunha, a relação de Machado de Assis com o leitor era igualmente forte, porém, a teoria do contista fluminense constitui-se de modo bastante diverso, isso porque a presença de um narrador pretensamente indiferente, como acontece na maioria das narrativas machadianas, instabiliza o texto e, consequentemente, amplia as possibilidades de leitura.

Nesse caso, o efeito do conto machadiano "não é apenas fruto da técnica ou da habilidade do escritor em lidar com elementos expressivos da linguagem que utiliza e cria, mas decorre principalmente do 'susto' que dá no leitor” (CUNHA, 1998, p. 107). Logo, compete ao leitor a opção de escolha de como ler a narrativa, levar ou não o susto. Entretanto, para desnudar uma história de amor infeliz ou então uma série de acontecimentos corriqueiros e dessa forma desvendar o "outro" texto, a ação do intérprete é fundamental. Nessa linha, os contos machadianos apresentam dois níveis narrativos: o primeiro, mais acessível, estabelece a história narrada, e o segundo, institui o texto subliminar sugestionado e aberto a múltiplas interpretações.

\section{Últimas intersecções}

O eixo temático do conto "A causa secreta" e o mote poético desenvolvido em "Suave mari magno" assemelham-se. Ambos retratam o gosto perverso pela degeneração como característica inerente ao ser humano. Com efeito, os atos sádicos expostos na narrativa e no poema são atribuídos a indivíduos pertencentes a núcleos sociais comuns, até mesmo os curiosos desconhecidos retratados no poema indicam uma vida regular, na medida em que caminham livremente pela rua. Não se trata, portanto, de painéis ocupados por personagens assumidamente acometidas 
por síndromes psiquiátricas; pelo contrário, os agentes ou observadores do sofrimento alheio nessas composições representam tipos "normais".

Formalmente, a narrativa segue o esquema tradicional de formulação contística: anúncio de um conflito - desenvolvimento - desfecho. Assim como acontece em "A causa secreta", o poema também apresenta um enredo com início, meio e fim. Nesse sentido, poderíamos identificá -lo como um mini-poema narrativo. Assim sendo, o primeiro quarteto lança o conflito, facilmente adaptável para o texto em prosa (Lembro-me que em certo dia de verão um cão envenenado morria), em seguida, ocorre o desenvolvimento e ápice desse conflito (nesse momento as reações convulsivas do animal são narradas) e por último, nos dois tercetos, há o desenlace da história: nenhum curioso passava sem se deter diante da cena demonstrando prazer.

A possibilidade de compreender os poemas machadianos pelo viés da prosa levou Cláudio Murilo Leal (2008) a creditar à poesia de Machado de Assis certa "vocação narrativa". No ensaio "Um poeta todo prosa" (1998), o pesquisador investiga a presença de procedimentos narrativos descrição de personagens, cenários, narrador, enredo - na produção em verso do autor e examina até que ponto o aproveitamento dessa linguagem foi benéfica à poesia machadiana. De acordo com o Leal:

É possível afirmar que a influência da prosa atuou de duas maneiras na poesia de Machado. Uma, negativamente, enfraquecendo a voz do poeta lírico, devido ao uso abusivo de lugares comuns e clichês, que reduzem a tensão da linguagem. Outra, de maneira positiva, trazendo para a poesia uma consciência humanística, ainda válida nos dias de hoje, inclusive ao exercer uma função ética, para que a literatura não se perca nos jogos fúteis das formas poéticas, autárquicas e vazias (LEAL, 1998, p. 214).

Nesse sentido, convém ressaltar a censura do eu-poemático em "Suave mari magno" ao comportamento do passante curioso que se mostra extasiado com o sofrimento alheio; conduta esta também verificada na narrativa de "A causa secreta", onde a personagem responsável pelas atrocidades contra o rato é desqualificada física e moralmente pelo narrador. Assim como sugestionado nessas produções, muitas vezes buscamos repelir e até mesmo desumanizar as ações sádicas relacionando-as a impulsos demoníacos, porém não sabemos "[...] se é o demônio quem 
empurra os seres humanos em direção à crueldade ou se não é uma tendência natural à crueldade que os leva a imaginar, como justificativa e motivo de excitação, uma relação com o diabo.” (ECO, 2007, p. 220). A decisão pertence ao leitor.

\section{Bibliografia}

ARISTÓTELES. Arte poética. [Tradução de Pietro Nassetti] São Paulo: Martin Claret, 2003.

ASSIS, Joaquim Maria Machado de. Obra completa em quatro volumes: edição anotada. [Organização Aloizio Leite Neto, Ana Lima Cecílio, Heloisa Jahn]. 2. ed. Rio de Janeiro: Nova Aguilar, 2008. v. 4.

CARO, Tito Lucrécio. De rerum natura. Tradução Agostinho da Silva. Introdução de E. Joyau e G. Rebbech. Rio de Janeiro: Globo, 1962.

CUNHA, Patrícia Lessa Flores da. Machado de Assis: um escritor na capital dos trópicos. Porto Alegre: IEL: Editora Unisinos, 1998.

. História da feiúra. [Tradução de Eliana Aguiar]. Rio de Janeiro: Record, 2007.

LEAL, Cláudio Murilo. O circulo virtuoso: a poesia de Machado de Assis. Brasília, DF: Ludens, 2008.

. Um poeta todo prosa. In: SECCHIN, Antonio Carlos. et al (Org.). Machado de Assis: uma revisão. Rio de Janeiro: In-Fólio, 1998. pp.

PEREIRA, Lúcia Miguel. Machado de Assis: estudo crítico e biográfico. 6. ed. rev. Belo Horizonte: Itatiaia; São Paulo: Edusp, 1988.

POE, Edgar Allan. O gato preto e outros contos. [Organização e Tradução de Guilherme da Silva Braga]. São Paulo: Hedra, 2008.

\section{Imagem}

Disponível em http://2.bp.blogspot.com/-NwezqnU1TEs/TrrjVi6a9II/ AAAAAAAAAac/Lfe4dOoPOuk/s1600/causa_secreta1.jpg. Consultado em 07/10/2012 
